Fan, L. (2015). Methodological path to the genesis of a digital translation. Linguistica Antverpiensia, New Series: Themes in Translation Studies, 14, 200-218.

\title{
Methodological path to the genesis of a digital translation
}

\section{Lingjuan Fan}

Ningxia University, China

University of Manchester, UK

fan.lingj@gmail.com

Because online digital writing has become an important means of text production, this paper argues that the core concept of genetic criticism, 'avant-texte', should be kept up-to-date with the new medium and environment. It will show how online comments in interactive and collaborative textual production should be recognized within the translation's genesis. The online comments on a widely read news translation in China's largest virtual translation community is used to showcase how these digital comments can be identified and examined to facilitate our understanding of the microhistory or genesis of news translation. Situated at the juncture of genetic criticism and translation studies, this paper concludes by addressing theoretical and methodological implications for conducting a genetic analysis based on the proposed analytical model.

\section{Introduction}

In Modern Manuscripts, Dirk Van Hulle (2014) proposes that "textual genesis after the "pass for press' moment could be called 'epigenesis"' (p. 214). He thus focuses on the tension and the division between avant-texte and text, between the unfinished and the finished, which is at the core of genetic criticism. While many modern literary authors have continued to revise and alter their texts after they have been sent to the printer, thus extending their works' geneses into the space of Van Hulle's 'epigenesis,' and creating challenges for future editors of their works, here I would like to analyse how online environments create designated spaces for this activity, generating new dynamics between translators and readers.

Translation research has taken a sociological turn by recognizing the broader social and technological context that shapes the translated text. Yet this understanding of the source text [ST] is still restricted to the single and fixed individual text that is to be reproduced in another language. To genetic critics, however, the ST incorporates a much wider and mingled source of original avant-textes (drafts, sketches, manuscripts etc.), leading to a published text. Since the 1980 s, empirical translation 
studies have studied the process of translation, and while recent work in literary translation studies has attended to production rather than product of translated literature (Davidson \& Skoulding, 2013; Deane-Cox, 2014; Scott, 2006), the focus remains on 'translated' texts, understood as final products. Large, multilingual corpora of translated texts have been used for researching the meaningful changes in translations (House, 2001, p. 200), but "examining corpora of texts, no matter how large or linguistically varied, still fails to address the need to include translation processes in research and resulting model(s)" (House, 2001, p. 45). Indeed translated texts are invariably born out of avant-textes, which inform the creative process of the text.

While a genetic perspective can certainly benefit process-oriented translation research, most genetic studies focus on literary texts written by canonical authors. In order to "investigate the way in which social marginality informs the way people write and rewrite", as urged by the genetic scholar Davis (2002, p. 101), this paper chooses a genetic analysis of a digital news translation produced by a volunteer translator and published by the largest online translation community in China (see Section 3). I will argue that the change of medium greatly influences the process and product of translation, demanding more research into the epigenesis of the translated text. I will treat online comments by readers within the digital space as exogenetic materials that will be integrated into the evolving translation by the translator. In genetic criticism exogenetic materials are external to avant-textes and texts (they can include notes, research materials, vocabulary lists, letters and diaries), which become endogenetic when integrated into the writing process (when they become avant-textes) (Debray-Genette, 1979).

To foreground the shifting medium of textual production and to offer a more complete microhistory of our case study, this paper will revisit the conceptualization of avant-textes, and update their definition for online textual production.

\section{Redefining avant-textes for a digital medium}

Genetic criticism is the study of the process of textual creation. To this end it uses avant-textes, which include any "draft documents that bear witness to the evolution of the work" (de Biasi, 2004, p. 38); for example: "outlines, scenarios, sketches, rough drafts, edited clear copies, a final manuscript, corrections on proofs" and so on (de Biasi, 2004, p. 38). Unlike traditional textual criticism, which aims to produce a polished edited version of a text, genetic criticism is interested in the "creative process and the material traces it [has] left in multiple drafts" (Van Hulle, 2014, p. 5); the central concern being to reconstruct the textual development of the final written document as can be ascertained from any existing documents (de Biasi, 2004, p. 2). 
However, the advent of Web 2.0 poses terminological and methodological challenges for genetic criticism. Avant-textes have been conceived of as physical materials, and defined as "manuscripts" and "documents" (de Biasi, 2004, p. 30). Yet, the new media landscape has digitized writing. Furthermore, interactions between authors and audience leave traces in the form of online comments which used to be excluded from the collection of avant-textes and the genesis of the work, for they were considered to be post-texts. As a result, the definition of key terms in genetic criticism, such as "genetic dossier" (de Biasi, 2004, p. 11), should also be kept up to date with the emerging digital materials. For instance, exogenetic materials continue to feed into the epigenesis of the translated text and the process of its creation.

If conceptual challenges are relatively easy to cope with, methodological difficulties require more empirical studies to explore. Genetic scholars debate genetic criticism's chances of adapting to the fast-changing medium of writing. Some believe the age of genetic criticism is drawing to an end because of the absence of previous drafts, erased by typing on the computer. Computers make the detection of previous versions challenging because digital writing automatically overwrites what was written previously (Mara, 2013). However, Roger Laufer (1993) calls on the use of technological tools to preserve digital manuscripts. Van Hulle (2014) and de Biasi (2004) also state that genetic criticism is not vanishing in the digital age; on the contrary, it is able to move towards more nuanced research facilitated by newly invented tools or functions, such as Apple's AutoSave and Versions. The creation of these software has indicated the existence of enhanced textual awareness outside the humanities. Believing that 'every version counts'; Apple has invented a product to automatically save the previous version of a text so their customers can "see every step" in the process of their writing (de Biasi, 2004, p. 240). However, although the use of keystroke logging (Ehrensberger-Dow, 2013) and Apple's AutoSave is technically sound, ethical issues of privacy and data protection must be resolved if used for analysis of others' work. This paper opts for identifiable online materials as its main sources for conducting textual genetic analysis.

Translation scholars have identified the collaborative and interactive features of text production in which online comments play a central role (Drugan, 2013). As collaborative translation and assessment become more common, readers are more able to see "others' contribution in real time and sharing resources" (Drugan, p. 101); as a result, "review and comment" are integrated into the "work cycle" to ensure the improvement of translation (Drugan, p.101). This open and sometime spontaneous creative process demonstrates interesting and different patterns compared with traditional media contexts (Desilets, 2007). The rapidly growing presence of online comments on translated texts can be used to fill the gap in genetic studies, and resolve the tension between 
"reception criticism" (Deppman, Ferrer, \& Groden, 2004, p. 2) and "textual production" (Deppman, Ferrer, \& Groden, 2004, p. 2)

The entry point of methodological adaptation lies in the analysis of previous drafts and the comments on the translation. Since no previous drafts were retrievable for this case study, comments are used as exogenetic materials that inform meaningful changes to the text made by the translator. Questions addressed include: i) How can we identify the avant-textes of a digital translation? ii) How do we code and analyse the comments to recover the genesis or microhistory of the translation? iii) What are the implications of researching avant-textes for genetic translation studies? Before presenting this genetic analysis of digital news translation, it is imperative to trace back to the crossroads of the theoretical development between translation studies and genetic criticism and show how these existing theories will aid our methodological exploration of genetic translation studies.

\section{Adapted avant-texte analysis}

Traditional genetic analysis consists of "specifying and classifying rough drafts", "deciphering and restoring" previous versions, and identifying features of changes (de Biasi, 2004, p. 50). This study has adapted the method into a digital setting by following three steps: i) identifying draft translation(s) using comments as exogenetic material for avant-textes; ii) coding changes in different versions of translations; and iii) recovering the editing process by following the interactions between the translator and his readers and diagnosing any patterns that might have emerged from the changes. I will first of all explain the conceptualization of comments as detection tools for genetic analysis before explaining the analytical model.

What is particularly novel in this case study is the analysis of the collaboration between translators and readers/other translators as it occurred in real time. Online comments leave trails of textual changes, directed by the interactions between the translator and readers. Comments on published translations resemble the exchanges made between the presenter and the audience at an academic conference. The questions can be roughly divided into those either related or un-related to the content of the presentation. Content-related data are most useful avant-textes because they provide clear clues to places where changes are made. Because interactive communications are carried on via a 'first-come, first-respond' manner, the sequence of the editing process can be detected by following the chronological order of the comments made. Readers' attention tends to be drawn to different aspects of a translation, so the comments tend to be disorganized; thus it is the researcher's task to identify, categorize, and select comments for analysis. 


\subsection{Identifying and coding avant-textes}

The methodological path illustrated here is a genetic study of a published translation of a English article entitled, "Han Han Finds a New Crowd to Irritate", published by the New York Times in 2011. ${ }^{1}$ The source text is a news article following the publication of three high-profile online articles by a Chinese outspoken writer named Han Han, one of the most influential people in the world according to Time magazine. The NYT news report was then translated by Jiang Lienong ${ }^{2}$, a 'celebrity' volunteer translator from Yeeyan (Yeeyan.org).

The virtual location of the news translation, Yeeyan, was created in 2006 by three overseas Chinese intellectuals who wished to fill in the knowledge gap between China and the US by translating the latest international information from English into Chinese. China now has the largest online population, but Chinese readers still face difficulties in accessing global information. On the one hand, most of them lack the foreign languages skills to understand the foreign media content; on the other, strict Internet surveillance means that some foreign websites are banned for political reasons. Translation thus steps in as a transforming power to make foreign media content accessible to Chinese readers. By 2014, Yeeyan has 400,000 registered users and 30,000 volunteer translators. The majority of them are Chinese university students. It has now established its international profile through news translation and various volunteer translation projects, widely appraised as a model of accessing international information through translation (Stray, 2010).

This news translation was selected for this research for the following reasons. First, the translated article concerns the most controversial and urgent socio-political issues in China. Han Han's blog articles are often censored in China because of his bold criticisms of social and political issues in China. Yeeyan is not only a site for accessing international information, but a channel for Chinese citizens to discuss pertinent socio-political problems, which is not always possible offline. We can observe how ordinary netizens, as translators and readers, engage with political topics and issues, and how the textual production may be influenced by self-censorship and institutional powers. Second, this translation enjoys high visibility in Yeeyan, having attracted 39,534 viewings, 65 praises and 80 comments, which is rare for a news translation, which can easily become forgotten a few days after publication. The study of these comments will help us understand the motivation of the translator and his readers in devoting so much time and effort to this piece of work. Finally, this news translation contains many examples of 'loop translation' - e.g. the ST published by the NYT contains a great proportion of English translations of Han Han's Chinese articles. The English news report was then assessed and translated into Chinese. Aware of this complicity, the translator has a strong sense of tracing back to "the origin" (Van Hulle, 2014, p. 20) of the ST. Thus the 
genetic concept of 'origin' converges with 'the ST' in translation studies, and is especially fit to explore a genetic perspective in translation research.

To what extent these avant-textes will be explored depends on how far a researcher wants to dig "upstream" (Van Hulle, 2014, p. 20). Though our data are mainly comments, other identifiable avant-textes are only of instrumental use in searching the upstream of the final translation. From the existing definitive text, the published translation, we can trace back firstly to the avant-texts of the translation, then further upwards to the avant-textes of the original news article. Due to space constraints, we will only focus on comments; other avant-textes will not be covered in detail in the analysis.

\subsection{Methodology}

The analysis is conducted in three procedures. First, 80 comments are closely examined to detect any changes made by the translator, often through his interactive discussion and negotiation with his readers. Second, we select the active collaborators with the translator by dividing the comments into content-related and non-content-related. Finally, the investigation digs further into the translator's intention behind making the changes and how his editing process is shaped by his interactions with the "environment", which includes his readers, translation resources, and the Yeeyan platform. This environment can be viewed as, in Van Hulle's (2014, p. 245) term the "extended mind" of the translator.

\section{Comments-driven genetic analysis}

Eight excerpts were identified as content-related and having been intensively negotiated between the translator and his readers in the textual development of the translation. The editing covers different aspects of linguistic semiotics, such as punctuation, format, diction, and, more frequently, the interpretation of the ST. To illustrate the changes made in editing, conventionally codes in genetic analysis are adopted here; for example, $<$ XXX $>$ as "added" and XXXX as "crossed out" (de Biasi, 2004, p. 57). To produce a more focused analysis, only examples with major influence on the editing of the translation are cited and analyzed; others, if loosely relevant to the research goal, are summarized to guide the understanding of the analysis.

Time is an important factor in retracing the microhistory of a translation. Online information shows clearly that the translation was published on the Yeeyan website within two days of the publication of the ST. We found that the first comment appeared 25 minutes (29 December 2011 at 18:16:21) after the publication of the TT (29 December 2011 at 
17:52:47), which is a very short gap between production and consumption; this is another advantage of online translation and publication. The first noticeable change started to occur when a reader with the screen name TTK addressed the translator at 19:19:15 on 29 December 2011. As an active collaborator of the translation edition, TTK paid meticulous attention to the diction and style of the translation. His intention of joining the conversation with the translator lay in his great curiosity for China's political prospects, as revealed from his initial comments.

The first comment explains his motivation for being a critic of the translation. He agrees with Han Han's opinion and says that, while revolution is not applicable in China, reform is also difficult to be advanced. Meanwhile, he eagerly expects a foreseeable political solution that will drag China out of its current standstill. His comment reveals that: “我好奇死了, 所幸的是我不用等太久了。” [I am so curious about that. Luckily, I don't need to wait long for the result]. ${ }^{3}$ TTK's comment reveals his and other readers' motive for acting as participants in the editing process of the translation. Han's original articles were censored and access to NYT's news website was also denied in China. Thus, Yeeyan became an alternative channel to trace the perception of Han Han's articles by the foreign media through translation.

It is not until 20 minutes later that TTK starts to comment on specific translation problems, as shown in Example (1).

(1) TTK: 2011-12-29 19:19:15

将 “ (其) 论断几近谄媚, (其文) 偏颇、堕落退步, 似已主动 放弃” 译为 [It's] almost predicated on flattery. It's biased and degraded, like he has surrendered voluntarily. 这样, 是不是失去 了原来文字的味道了? 虽然意思一样, 译文平淡了许多。翻译真 是太难了。

[...In this case, would the translation lose the original flavor? Though they mean the same thing, the translated version is rather plain. What a difficult task to translate!]

Jiang: 2011-12-29 19:36:55

回译的重要原则就是尊重原始文本, 这个出发点是我们相信原译 者具有同等的职业操守, 与回译者一样尊重原始文本, 并未有意 识篡改原文。

[An important principle for loop translation is to respect its original text, which derives from our belief that the original translation adheres to his/her professional ethics and no deliberate intervention or manipulation has been made.]

TTK suggests that the translation seems flavorless compared to the ST. 18 minutes later, the translator Jiang reacts defensively that he is justified in retaining the plain flavor of the translation, because he has identified 
this part as being a 'loop translation'. He backs up his argument with the traditional translation principle of remaining true to the original, and he adopts an authoritative tone: "An important principle of loop translation is to respect its original text". In the case of loop translation, the translated sentences in the ST should be recovered and made as close as possible to the original Chinese version. To demonstrate that it is his deliberate choice to stick to professional translation practice, rather than his deficiency in mastering the Chinese language, he finishes his response with an unusual combination of nine four-character-based Chinese idioms, including it is “易如反掌” [super easy] to turn the ST with “plain' words into “雍容华贵” [glorious and splendid] translation, but “还原语言平淡最 难。" [The most difficult of all is to retain the plain flavor of the ST].

Example (1) is a rare example of a translator rebutting the critique of his readers without any reservation, although in following cases he at least presents himself as happy to negotiate and 'improve' the text, as demanded by his viewers. Seven minutes after the translator's unreserved objection to TTK's critique, TTK quickly moves his attention from paragraph 3 to 10 to challenge the translator's treatment of being 'selfabsorbed'. The detected drafting process results in three parallel, comparative texts between the ST and two versions of the TT, followed by online comments used as avant-textes, illustrated in Example (2).

(2) ST: These posts will probably make him more popular, not less, even though Han takes a dim view of his fellow citizens. In his view, they are self-absorbed, utilitarian and atomized.

T1: 即使韩寒或许有那么一点䅐视自己的同胞, 但这几篇帖子最后 很可能增加一一而非减少——他的人气。在他看来, 他的同胞们㚗 我陶醉、急功近利、形同一盘散沙。

[Even though Han Han may look down a bit on his fellows, these blogs eventually may increase - rather than reduce his popularity. In his view, they are self-intoxicated, utilitarian and atomized.]

$\mathrm{T} 2$ : 即使韩寒对自己的同胞不以为然, 〈甚至可能不太满意〉, 但这 几篇帖子最后很可能增加一一而非减少—他的人气。在他看来, 他的同胞们专注自我、急功近利、形同一盘散沙。

[Even though $\underline{\text { Han Han does not take his fellows seriously, }<\text { and even }}$ is not very happy with them $>$, these blogs eventually may increase, rather than reduce, his popularity. In his view, they are self-centered, utilitarian and atomized.] (my emphasis)

TTK : 2011-12-29 19:42:02

我觉得原文不是说韩寒有些䅐视自己的同胞, 而是对他们持悲观态 度(take a dim view); “self-absorbed” 我认为译为 “自私自利” 更 准确。另, 此段末, “网络活动主义者” 似乎也不准确。 
[I don't think the ST means that Han Han despises his fellows, but takes a pessimistic view (take a dim view); "self-absorbed" I think it should be more accurately put, rather than "selfish".]

Jiang: 2011-12-29 20:03:00

to take a dim view 中的 dim view 国内似有很多译为 “悲观” 一一或 更准确点 “不乐观” 的例子。但这个短语本身含义是 to regard disapprovingly and unfavorably。客观来讲, 如果你 take a dim view, 那么你不以为然, 而且通常带有厌恶、抵制、不满情绪, 所以我译 为了 “或许有那么一点藐视” 。可能也不太准确。当时想了几个与 “视” 搭配的词, 轻视、小视等, 主要是想还原 dim view 的结构。 看来这里还是意译比较好。

["dim view" in "to take a dim view" seems to have been repeatedly translated into "pessimistic" or, more accurately, "not optimistic" in domestic translation practice. But this phrase actually implies "to regard disapprovingly and unfavorably". Objectively speaking, if you take a dim view, then you do not take it seriously, and often with the implication of disgust, resistance, and discontent; therefore I translate it as "maybe slightly looking down upon his fellows". My translation may not be particularly accurate. I have thought of several collations with “视” (view), mainly because I want to reproduce the structure of "dim view". It seems that a free translation applies better here.]

10 minutes after TTK's comment, the translator Jiang responds again in a rather professional tone; though he continues to resist the criticism, he does so in a more strategic way. He first acknowledges that the phrase "take a dim view" has often been translated as "pessimistic view" by Chinese translators, as understood by TTK, but then vetoes this interpretation by citing definitions from reference books. While acknowledging the flaws of his translation, he is actually pointing out TTK's superficial understanding of this term. He further explains his thoughts on the matter while translating "a dim view". To reproduce both the content and the style, he prefers to use "藐视”, which means "look down upon". Despite his explicit explanation, he has decided to change the word, in the translator's words, “既然你一眼就发现不对, 那我还是 改改吧, 暂意译为“专注自我” [Since you find the word problematic, I'd better change it a little bit, so let's pencil in “专注自我” (selfcentered)]. We can sense his reluctance to change, but also his growing awareness of his recipient's perception of his text.

12 minutes later, TTK objects to the translator's version of “专注 自我” [self-centered]: “不行” [No way], because the use of “self-centered” “就没有原文的贬义了”[ would lose the pejorative meaning of “selfabsorbed"]. Their debate resumes an hour later. Before that, TTK does not retreat from the translator's lengthy lecture on the subtle differences in lexical terms. He moves further down to the end of the article to 
question the translator's projection of Han's image in a Chinese TV show program. According to TTK, the translator seems to unfairly present Han as submissive to education experts and his audience's criticism, because the translation describes Han as “干坐了一个小时”[sitting uncomfortably for an hour]. This time, Jiang readily agrees with the comment and promises to check it out by reviewing the program, as shown in Example (3).

(3) ST: He appeared on a Chinese state-television broadcast and sat through an hour of criticism from education experts and audience members.

$\mathrm{T} 1$ : 后来现身中央电视台一档节目, 王坐子一个小时, 承受来自教 育专家和观众们的批评。

[Later he appeared on a Chinese state-television program and sat uncemfortably for an hour, suffering criticisms from the education experts and the audience.]

$\mathrm{T} 2$ : 后来他现身中央电视台一档谈话节目, 二个小时〈从头到尾〉承受 〈了来自教育专家和观众的批评。

[Later he appeared on a Chinese state-television program and, suffering criticism for $<$ the whole $>$ hour from education experts and the audience.] (my emphasis)

TTK : 2011-12-29 19:53:41

一原文没有 “干坐” 中 “干”之意吧, “干坐” 可有光挨打 不开火的意思。

[I assume that there is no implication of “干” (boringly) in the ST: “坐” (sitting uncomfortably) implies that he was incapable of fighting back while being attacked.]

Jiang: 2011-12-29 20:15:16

是这样的, 你指出的点, 都是我很犹豫的地方。我以前看过那个视 频很多遍, 印象中剪辑以后确实就给人类似 “干坐” 的感觉。虽然 我们知道韩寒不会光挨打不开火, 但作者这里的口气几乎就是这样 了: sat through an hour of criticism。为了译得更准确, 我现在重新 看一遍那个节目, 一个小时以后再答复你。

[What you have pointed out are all my reservations. I have seen that video, and my impression is that the edited video presents Han Han as "sitting there uncomfortably under attack". Although I know Han Han would not possibly sit there under attack without offering any defense, the tone of the writer suggests he did so with phrase: "sat through an hour of criticism". To make sure it is more accurate, I will now watch that program again and get back to you in an hour.] 
From the translator's response, we get a strong sense of the professional ethics he adheres to: his meticulous care in prioritizing the 'origin' of the information. In Example (3), he is quite capable of tracing 'upstream' to the origin of the ST. He may not have a sense of genetic scholarship, but he is certainly aware of the genetic process of translating and its potential for misinterpretation. The TV show video that he previously consumed is also an exogenetic resource for his translation, which responds to how the way the program was edited presents Han as a weak activist. The translator's subjective impression of that program thus leaves its mark on the drafting process of his translation by adding "sit uncomfortably" to the TT. The next morning, he briefly introduces "foreignization" and "domestication" (Venuti, 1995) as both valid translation approaches, but he stresses again his primary duty as recovering the origin. Compared with previous negotiations between Jiang and his readers, Jiang seems to be more alert to his own subjective interpretation, and thus is more willing to compromise if readers point out any information missing from the original.

TTK, as an avid reader, must have read the translation more than once, as the next question he raises goes back to the topic of the news story. This time, he challenges Jiang's translation of the title and subheading.

(4) ST: Dispatches by Evan Osnos

$\mathrm{T} 1$ : 欧逸文为您分拣

[Categorized by Evan Osnos]

$\mathrm{T} 2:\langle$ 中国来信〉一一欧逸文要闻速报

$[<$ Letter from China $>$-Fast delivery of major news from Evan

Osnos](my emphasis)

TTK: 2011-12-29 21:23:19

[...] 另外 “Dispatches by Evan Osnos” 为何译作 “欧逸文为您分 拣” ? 我觉得译为 “欧逸文发来的快件” 更准确, 这个栏目的确对 国内事件有较为及时的反应。

[... As well, why translate "distributed by Evans Osnos?” into “欧逸 文为您分拣” I feel it would be more accurate to put it as “欧逸文发 来的快件” (Fast delivery sent from Evans Osnos)].

(5) ST: Han Han Finds a New Crowd to Irritate

$\mathrm{T} 1$ : 韩寒找到新目标

[Han Han finds a new target.]

T2: 韩寒找到新目标, 〈又有一帮人被挑怒〉

[Han Han finds a new target, < and another group is irritated $>$ ] (my emphasis) 
TTK : 2011-12-29 21:23:19

\author{
!!没注意题目。“Han Han Finds a New Crowd To Irritate” 哪有 \\ “找到新目标” 的意思?
}

[!! Pays no attention to the title. Where is "find the new target" in the original title 'Han Han Finds a New Crowd To Irritate'?]

Jiang: 2011-12-29 22:05:54

dispatch 确实处理过头了, 甚至译成了 sort。之前没看过他那个栏 目, 大概浏览了一下, 确实与分拣无关, 就是最常见的意思 “要闻 速报”。标题是意译的, 原文那个 new crowd 就是他 irritate 的新 (new) 目标 (target, as in an object of criticism or attack, 即批评或 攻击的对象，见《美国传统词典》; 又, [...] 见《现代汉语词 典》)

[It is true that "dispatch" has been overtranslated, and even turned into "sort". I have not read his colomn. I since went throught it and found that it has nothing to do with “分拣” (distribution), and the most general meaning should be “要闻速报” (fast delivery of major news). The title is a free translation...(target, ... see Amerian Traditional Dictionary; also, ... see Modern Chinese Dictionary)]

Jiang's translation of title is obviously problematic due to his misunderstanding of "dispatch". Errors like this could easily have been corrected by post-drafting editing, which suggests that Jiang's draft has not gone through a thorough revision before its publication on Yeeyan. However, he does not adopt the suggested wording of TTK, but changes it to “要闻速报” [fast delivery of major news], a more idiomatic version. He then defends his translation of "target" with reference to other avanttexts in his translation: prestigious dictionaries in English and in Chinese. His reaction to TTK's criticism is consistent with his previous ones. On the one hand, he is happy to admit his limitations, but on the other he is quite resistant to being guided by lay readers, or at least those who are presumably less informed about translation theories and ethics.

Then another reader, with the screen name dingdingdang, joins the conversation between Jiang and TTK, at around 22:30 on the same day. He supports TTK's view that the epithet "self-absorbed" often conveys a negative meaning. He even posts a literary text in English in which the very phrase is used with a negative connotation. Unconvinced, Jiang, in his typical fashion, provides a lengthy argument about how a neutral word can be interpreted either positively or negatively depending on different collocations. Citing the word "ugly" for example, he says: “比如 [for example] 丑 ugly、真丑 very ugly、非常丑 really ugly、非常非常 丑 seriously ugly [...], 都可以是客观中立的评价[all can be neutral evaluations]; 但[but]太他妈丑 fucking ugly 就掺杂了主观情感[has intense subjective emotional connotation], 赋予语言“贬义”[and 
implies a] derogatory sense, 或口语所谓 [or orally is] "expressive of low opinion". He adds that in the Chinese cultural context, "self-absorbed" can be a neutral word, because staying away from others' troubles is a philosophy of life, rather than a sign of selfishness. He justifies his decision and declares that no change will be made to this word.

Nine minutes later, TTK indicates his strong objection to the translator's choice: “两回事, 决不能这么翻。” [These are totally two different matters. It cannot possibly be translated in that way]. He further explains that 'self-absorbed' has a sense of narcissism, which contradicts the meaning of the ST. Jiang, slightly offended by TTK's adamant attitude, drops any attempt to reach agreement, and turns to challenge TTK to produce a better version. TTK is somewhat caught by surprise by Jiang's request and is totally unprepared for the challenge. To alleviate the tension between him and Jiang, TTK softens his tone and advises the translator to put an end to the revision. In his words, “这篇文章文笔一般, 内容也算不得多深刻或是新奇, 为此花费这么多精力, 够了。到此为止 吧。期待你的文学类的高质量译文 [...]" [This article is not particularly well-versed, and its content has nothing profound and new in it. You have devoted so much energy to its translation. It's time to put it to an end. I look forward to your high quality literary translation...]. This comment is in sharp contrast to his first comment on the translation in which he showed genuine interest in the social implications of the news article. His perception of news texts as inferior to literary texts is also a quite restricted view, but one typical among lay translation readers.

Jiang responds early the next morning and politely declines TTK's suggestion. He views this translation as a chance to discuss the sorts of Chinese political issues which cannot openly be done offline. He certainly senses the bias of TTK towards news translation, and alerts his readers to the fact that the importance of news stories cannot be underestimated. Jiang demonstrates his strong determination to improve this translation, and stresses that, because news stories can easily become out-of-date, he will waste no time in producing and polishing the translated version for his readers.

The next round of major revision is concerned more with formal and grammatical issues which were raised on 31 December, one day after the first round of editing. A reader with the screen name mindyoy draws the translator's attention to his misuse of “写到” [write about], and urges it to be changed to “写道” [write as follows:]. This comment is followed by an intensive discussion of the translation's misuse of full stops and quote marks. For guidance, mindyoy provides the translator with information about a reference book entitled “标点符号学习与应用”（林 穗芳注, 人民出版社） [The study and application of punctuation, with notes by Lin Suifang, published by People's Publishing House]. After nearly three hours, the translator humbly admits that his use of punctuation is “文盲用法” [illiterate], and confirms that his mistakes have been corrected. The sorts of changes made are illustrated by Example (6). 
(6) ST: Han's lament "lacks honest discourse and is too acquiescent. [It's] almost predicated on flattery. It's biased and degraded, as if he has surrendered voluntarily".

TT1: 韩寒的悲叹 “之于认真的论述, 过于默契。（其）论断几近谄 媚, (其文) 偏颇、葄落退步, 似已主动放弃。”

[Han's lament "lacks honest discourse and is too acquiescent. [It's] almost predicated on flattery. It's biased and degraded, as if he has surrendered voluntarily".]

TT2: 韩寒的悲叹 “之于认真的论述, 过于默契〈” 〉。〈“〉(其) 论断几近谄媚, (其文) 偏颇、荫落退步, 似已主动放弃。”

[Han's lament "lacks honest discourse $<$ " $>$ and $<$ " $>$ is too acquiescent. [It's] almost predicated on flattery. It's biased and degraded, as if he has surrendered voluntarily".]

The discussion of punctuation continues until 16:47 on 31 December. We can assume that the translator has revised all his punctuation errors by then, revealed from the grateful attitude he adopts towards his critics.

The third round of revision goes back to the content of the translation. On 1 January 2012, a reader with the screen name meihelan points out two potential problems with the translation in her comment. Recovered versions are shown respectively in Examples (7) and (8), followed with discussions about their corrections.

(7) ST: Now, for precisely the reasons that made Han interesting enough to profile him in the magazine in July, [...]

$\mathrm{T} 1$ : 本刊今年七月曾报道过韩寒, 因为他行事背后的动机引人好 奇不断;

[Our magazine has reported Han Han, because the motivations behind his actions attract continuous curiosity.]

$\mathrm{T} 2$ : 本刊今年七月曾报道过韩寒，因为他行事背后的理由引人 好 奇不断;

[Our magazine has reported Han Han, because the reasons for his actions attract continuous curiosity;] (my emphasis)

(8) ST: It is a measure of Han's influence that he did more to spark a debate over censorship, dissent and revolution.

$\mathrm{T} 1$ : 韩寒利用了自己的影响力, 激发了对审查、异见, 以及革命 等主题的辩论。

[By taking advantage of his own influence he did more to spark a debate over censorship, dissent and revolution.]

$\mathrm{T} 2$ : 韩寒凭借自己的影响力, 激发了对审查、异见, 以及革命等 主题的辩论。

[Han Han, by relying on his own influence he did more to spark a debate over censorship, dissent, and revolution.] (my emphasis) 
meihelen : 2012-01-01 09:01:03

1. 第一句中我看不出来有 “因为他行事背后的动机引人好奇不 断” 的意思。直译好像是： “因为有理由使人对他有足够的兴趣; 如今, 正是基于同样的理由...”。我理解这些理由不限于 “动 机” , 可能还有性格、思维方式, 甚至赛车经历等等。2. 第二 句不太赞成译为 “利用自己的影响力, 激发了” ( H takes advantage of his influence to spark ... ) , 因为这好像是他主动去 做的事情, 而文中描述的是一个客观现象。[1. I cannot see from the first sentence that "Because the motivations for his actions attract continuous curiosity". To put it literally, it seems to mean that "Because there are reasons for people to be curious about him; and now, based on the same reason...". My understanding of the causes are not limited to "motivations"; there may be personality, mindset, his racing car experience, etc. 2 . I don't quite agree with your translation of the second sentence...,because it was something he did it voluntarily, but what the text says is an objective phenomenon. ]

Jiang : 2012-01-01 10:26:19

针对第二点, “利用” 确实不准确, 暗示了太多的主观能动性。

“凭借” 如何? []. 我认为韩寒此次事件是有意为之, 作者 应该也是这样的态度, 否则他不会讲 “所以这次他可能低估了这 几篇文章将会造成的影响”, 言下之意, 韩寒事前有所打算。而 您的解读在这两句都从更客观的角度切入。

[As to the second point, "use" is truly not accurate; it implies a strong sense of subjectivity. How about "by relying on"? ... I believe this event of Han Han (publication of his blog articles) had been built on deliberate planning; otherwise, he would not say, "so he may have underestimated the influence of these articles". The implication is: Han Han had planned that. But your interpretation has been made from a more objective perspective.]

Jiang : 2012-01-01 13:26:40

我也觉得两种都有道理, 可能原文本身就模棱两可, 那么此处可 能还是改为 “理由” 比较保险, 因为 “理由” 应该可以包含 “动 机”。

[I also think both are applicable, due to the ambigous ST. Then it is safer to change it to "reason", because it contains the meaning of "motive".] 
About an hour or so later, the translator responds to the first question with modesty, and updates the translation with his own alternative choices. Three minutes later, he replaces "motivations" with "reasons", though there is only a slight difference between the two. By this stage, the translation has undergone three rounds of major revisions, directed by the readers. There may be further changes, but Jiang announces in his final comment that further changes cannot be displayed, because the platform owner Yeeyan restricts further revision of the translation once the translation is assessed as being sufficiently qualified. To Yeeyan, there is a limit to how polished the translated product should be, and the emphasis is put on efficiency and accessibility rather than solely on improving the translation's quality.

\section{Conclusion}

The translator and his readers made an archaeological investigation of the original information. The principle of 'going back to the origin' was never declared by the translator or his readers, but explicitly shown through their reference to other exogenetic materials in the 'upper stream', such as Han's Chinese article, the original Chinese quotations in the ST and even the TV show which is mentioned in the ST. This archaeological path leads us to the 'extended mind' (Van Hulle, 2014) of the translator, represented by a number of recipients who have examined the translation draft closely, and the translation platform which facilitates and restricts the drafting process by enabling instant comments but restricting further revision. Editors who are intrusive forces in printed media are nearly invisible here. The transition from private creation to semi-public publication also situates the translator at the stage of interrogation. Questions are raised instantly, and he has an obligation to justify every decision he makes or readily acknowledge his limitations. As a result, the original solitary and coherent text marked with the translator's individual characteristics is fragmented somehow by the co-authoring process. The process of textual production is thus greatly altered: from an isolated and intuitive production to a crowded social engagement. Textual stability is stirred, not by "scribal corruptions" (Sullivan, 2013, p. 6) or "careless copyists" (Sullivan, 2013, p. 6) in printed media, but the fluidity of authorship.

Collaborative textual production demands that the translator holds his audience's need in mind, rather than complete the translation as a dutiful task. However, it would be misleading to conclude that the role of the translator is reduced to one of partner of his readers. Apart from the editing of punctuation, he invariably adopts the tone of academic coaching, backed with frequent references to orthodox translation discourse, which can be overwhelming enough to silence his lay readers' objections, though some evidence he cites, such as 'foreignization' and 
'domestication', are known to translation scholars as flawed by dichotomy.

These concepts, genetically derived from translation research, are applicable to textual genesis. It is not only the concept of 'the source text' that remains central to the research objects of translation studies, but translation theories such as 'foreignization' and 'domestication' can be perceived as a part of the process of the author's synthesis of original composing elements repacked for a targeted readership through a 'translation' of ulterior structures (Van Hulle, 2004). This reveals the conjunction between genetic criticism and translation studies which is yet to be explored in great depth.

The new form of digital production demonstrated here challenges the essence of 'avant-textes'. The demonstration of collaborative translation processes fostered by online environments renders the production of the final text difficult to define with the traditional singleauthor genetic model. Yet textual genetics offers a methodology, tools and means for observing new processes engaged by collaborative digital writing, editing and translating. This can only enhance future studies in other fields of translation, such as non-professional translation (PérezGonzález \& Susam-Saraeva, 2012) and crowdsourcing translation (O’Hagan, 2009).

\section{References}

Bellemin-Noël, J. (1972). Le texte et l'avant-texte: Les brouillons d'un poème de Milosz. Paris: Larousse.

Bellemin-Noël, J. (2004). Psychoanalytic reading and the avant-texte. In J. Deppman, D. Ferrer, \& M. Groden (Eds.), Genetic criticism: Texts and avant-textes (pp. 28-36). Philadelphia, PA: University of Pennsylvania Press.

Davidson, I., \& Skoulding, Z. (2013). Placing poetry. Spatial practices: An interdisciplinary series in cultural history, geography and literature. Amsterdam: Rodopi.

Davis, O. (2002). The author at work in genetic criticism. Paragraph, 25(1), 92-106.

De Biasi, P-M. (2004). Toward a science of literature: Manuscript analysis. In J. Deppman, D. Ferrer, \& M. Groden (Eds.), Genetic criticism: Texts and avanttextes (pp. 36-68). Philadelphia, PA: University of Pennsylvania Press.

Deane-Cox, S. (2014). Retranslation: Literature and reinterpretation. London: Bloomsbury.

Debray-Genette, R. (1979) Génétique et poétique: Le cas Flaubert. In L. Hay (Ed), Essais de critique génétique (pp. 21-67). Paris: Flammarion.

Deppman, J., Ferrer, D., \& Groden, M. (2004). Introduction: A genesis of French genetic criticism. In J. Deppman, D. Ferrer, \& M. Groden (Eds.), Genetic criticism: Texts and avant-textes (pp. 1-16). Philadelphia, PA: University of Pennsylvania Press. 
Desillets, A. (2007). Translation wikified: How will massive online collaboration impact the world of translation? NRC Publications Archive, Retrieved from https://archive.is/o/rXFaz/http://nparc.cisti-icist.nrc-cnrc.gc.ca/npsi/ctrl?acti on=rtdoc\&an=8913226 (accessed 20 August 2015).

Drugan, J. (2013). Quality in professional translation: Assessment and improvement. London: Bloomsbury.

Ehrensberger-Dow, M., \& Perrin, D. (2013). Applying a newswriting research approach to translation. Target, 25(1), 77-92.

House, J. (2001). Quality of translation. In M. Baker \& K. Malmkjær (Eds.), Routledge encyclopaedia of translation studies, (pp. 197-200). London: Routledge.

Laufer, R. (1993). Les manuscrits des écrivains. In L. Hay (Ed.), Le manuscrit électronique (pp. 224-237). Paris: CNRS Edition.

Mara, O. M. (2013). Nuala O'Faolain: New departures in textual and genetic criticism. Irish Studies Review, 21(3), 342-352.

Munday, J. (2013). The role of archival and manuscript research in the investigation of translator decision-making. Target, 25(1), 127-140.

Munday, J. (2014). Using primary sources to produce a microhistory of translation and translators: Theoretical and methodological concerns. The Translator, 20(1), 64-80.

O'Hagan, M. (2009). Evolution of user-generated translation: Fansubs, translation hacking and crowdsourcing. The Journal of Internationalization and Localization, 1(1), 94-121.

Pérez-González, L., \& Susam-Saraeva, S. (2012). Non-professionals translating and interpreting. The Translator, 18(2), 149-165.

Schäffner, C. (1997). From "good" to "functionally appropriate": Assessing translation quality. In C. Schäffner (Ed.), Translation and quality (pp. 1-5). Clevedon: Multilingual.

Scott, C. (2006). Translating the literary: Genetic criticism, text theory and poetry. In S. Bassnet \& P. Bush (Eds.), The Translator as writer (pp. 106-108). London: Continuum.

Sullivan, H. (2013). The work of revision. Cambridge, MA: Harvard University Press.

Van Hulle, D. (2004). Textual awareness: A genetic study of the late manuscripts by Joyce, Proust, and Mann. Ann Arbor, MI: The University of Michigan Press.

Van Hulle, D. (2014). Modern manuscripts: The extended mind and creative undoing from Darwin to Beckett and Beyond. London: Bloomsbury.

Venuti, L. (1995). The translator's invisibility. New York, NY: Routledge. 
1 Osnos, E. (2011) Han Han finds a new crowd to irritate, The New York Times, 28 December, http://www.newyorker.com/news/letter-from-china/han-han-finds-anew-crowd-to-irritate (accessed 20 August 2015).

2 江烈农[Jiang, Lienong] (2011) 韩寒找到新目标, 又有一帮人被挑怒 [Han Han finds a new target, and another group is irritated], Yeeyan, 29 December, http://select.Yeeyan.org/view/245405/243116 (accessed 20 August 2015).

3 All translations in square brackets are my own. 